\title{
The appropriate troponin T level associated with coronary occlusions in chronic kidney disease patients
}

\author{
Yuwares Sittichanbuncha' \\ Pungkava Sricharoen' \\ Panvilai Tangkulpanich' \\ Kittisak Sawanyawisuth ${ }^{2,3}$ \\ 'Department of Emergency Medicine, \\ Faculty of Medicine, Ramathibodi \\ Hospital, Mahidol University, Bangkok, \\ ${ }^{2}$ Department of Medicine, Faculty of \\ Medicine, ${ }^{3}$ Research Center in Back, \\ Neck, Other Joint Pain and Human \\ Performance (BNOJPH), Khon Kaen \\ University, Khon Kaen, Thailand
}

This article was published in the following Dove Press journal:

Therapeutics and Clinical Risk Management

4 August 2015

Number of times this article has been viewed

Background: High-sensitivity troponin T (HS Trop T) plays an important role as a diagnostic marker for acute coronary syndrome. It is also related to cardiovascular outcomes. HS Trop T levels may be varied in individuals with renal dysfunction. This study aimed to find the appropriate HS Trop T cutoff points in chronic kidney disease (CKD) patients who had coronary artery occlusion.

Patients and methods: The study was conducted at the Emergency Department, Ramathibodi Hospital, Mahidol University, Thailand. CKD patients stage 3-5 who had HS Trop T levels after 2 hours of chest pain and had coronary angiographic results were enrolled. Patients were divided into two groups: those who had significant occlusion of more than $70 \%$ of a coronary artery as the coronary artery disease (CAD) group and the non-CAD group.

Results: In total, 210 patients met the study criteria. There were 132 patients $(62.86 \%)$ who had significant stenosis of coronary arteries by coronary angiograms. The average age (standard deviation) of all patients was 71.02 (9.49) years. HS Trop T levels were significantly higher in all CKD patients with CAD than the non-CAD group ( 0.4973 versus $0.0384 \mathrm{ng} / \mathrm{mL}$ ). Sex and HS Trop T levels were significantly associated with CAD by multivariate logistic regression analysis. The HS Trop T level of $0.041 \mathrm{ng} / \mathrm{mL}$ gave sensitivity and specificity of $65.91 \%$ and $75.65 \%$, respectively, for CAD.

Conclusion: The HS Trop T level of $0.041 \mathrm{ng} / \mathrm{mL}$ provided diagnostic properties for established coronary artery occlusion in CKD patients.

Keywords: high-sensitivity troponin T, acute coronary syndrome, coronary artery occlusion, chronic kidney disease, sensitivity, specificity, coronary angiogram

\section{Introduction}

Acute coronary syndrome (ACS) is a common disease at emergency departments, and has high morbidity and mortality. ${ }^{1}$ Cardiac biomarkers are a useful diagnostic tool for ACS. ${ }^{2-4}$ High-sensitivity troponin T (HS Trop T) is very specific to myocardial tissue, and a level of more than $0.014 \mathrm{ng} / \mathrm{mL}$ has specificity to acute myocardial infarction in normal renal function patients. ${ }^{5}$

Chronic kidney disease (CKD) is a common disease in clinical practice and increases risk for ACS. Serum Trop T levels of renal dysfunction patients may be higher than the normal population, resulting in higher cutoff points. ${ }^{6}$ The cutoff point of HS Trop T for ACS with renal dysfunction may be higher than normal population. ${ }^{7,8}$ The diagnosis of ACS may need to be confirmed by coronary angiogram, but some studies have used clinical diagnosis of ACS. ${ }^{7,8}$ This study aimed to find the appropriate HS Trop T cutoff points in CKD patients who presented with ACS and had coronary

Correspondence: Kittisak Sawanyawisuth Department of Medicine, Faculty of Medicine, Khon Kaen University, 123 Mittrapap Road, Khon Kaen, 40002, Thailand

Tel +6643363664

Fax +66 43348399

Email kittisak@kku.ac.th
Therapeutics and Clinical Risk Management 20 I5: I I I|43-I I47

II 43

Dovepress

http://dx.doi.org/10.2147/TCRM.S8567| (c) (i) (5) 2015 Sittichanbuncha et al. This work is published by Dove Medical Press Limited, and licensed under Creative Commons Attribution - Non Commercial (unported, v3.0) License. The full terms of the license are available at http://creativecommons.org/licenses/by-nc/3.0/. Non-commercial uses of the work are permitted without any further Press Limited, provided the work is properly attributed. Perissions beyond the scope of the License are administered by Dove Medical Press Limited. Information on how to request permission may be found at: http://www.dovepress.com/permissions.php 
artery occlusion by coronary angiogram. Factors associated with coronary occlusion in CKD patients who are suspected to have ACS were also studied.

\section{Patients and methods}

The study was conducted at the Department of Emergency, Ramathibodi Hospital, Mahidol University, Thailand. CKD patients stages 3-5 who had HS Trop T levels (Hoffman-La Roche Ltd, Basel, Switzerland) after 2 hours of chest pain and had coronary angiographic results were enrolled. Patients who had received hemodialysis therapy or who had been diagnosed with non-coronary artery disease (non-CAD) by coronary angiogram were excluded. The study period was between June 1, 2010 and June 30, 2013.

Eligible patients were identified by using International Classification of Diseases 9 code 88.5 (clinical medication procedure code). Charts of eligible patients were retrospectively reviewed. Baseline characteristics, comorbid diseases, medications, history of smoking, HS Trop T levels, serum creatinine, and coronary angiographic results were recorded. CKD was classified by estimated glomerular filtration rate (eGFR) as stages 3-5 with eGFR of $31-60,15-30$, and $<5 \mathrm{~mL} / \mathrm{min} / 1.73 \mathrm{~m}^{2}$. eGFR was calculated by the Chronic Kidney Disease Epidemiology Collaboration formula. Serum creatinine on the date of the emergency room visit was used to calculate eGFR.

ACS was diagnosed by clinical findings of chest pain, HS Trop T, and ECG. ${ }^{3}$ The thrombolysis in myocardial infarction (TIMI) risk score was calculated. ${ }^{9}$ Significant CAD was defined by the presence of coronary artery occlusion of more than $70 \%$ of the culprit coronary artery or arteries.

\section{Statistical analyses}

Patients were divided into two groups by significant occlusion of more than $70 \%$ of a coronary artery as CAD and non-CAD. Baseline and clinical characteristics of patients in both groups were compared using descriptive statistics. Univariate logistic regression analyses were applied to calculate the crude odds ratios (ORs) of individual variables for CAD. All clinically important variables or results of univariate analyses with a $P$-value less than 0.10 were included in subsequent multivariate logistic regression analyses. Analytical results were presented as adjusted ORs and 95\% confidence intervals. Various cutoff points of HS Trop T were calculated by using receiver operating characteristic (ROC) analysis. The areas under ROC curves, sensitivity, specificity, and predictive values of all cutoff points were also executed. The association of HS Trop $\mathrm{T}$ levels and various factors were also calculated by multivariate logistic regression analyses. All data analyses were performed with Stata software (StataCorp LP, College Station, TX, USA). The study protocol was approved by the Ethics Committee in Human Research, Mahidol University.

\section{Results}

There were 1,550 patients who had HS Trop T results and coronary angiographic results. Of those, 282 patients met the study criteria. We excluded 72 patients due to hemodialysis (42 patients), inappropriate time of HS Trop T level (22 patients), stress-induced cardiomyopathy (five patients), and pulmonary embolism (three patients). In total, 210 patients were included in the analysis. There were 132 patients $(62.86 \%)$ who had significant coronary artery stenosis by coronary angiogram. Triple-vessel disease was the most common CAD (83 patients); double-vessel disease and single-vessel disease were found in 26 and 23 patients, respectively.

The average age (standard deviation) of all patients was 71.02 (9.49) years. Being of male sex, having diabetes mellitus, and significantly higher TIMI risk scores were found in the CAD group (Table 1). The mean eGFR of CAD was significantly lower in the CAD group than the non-CAD group: 38.91 versus $42.81 \mathrm{~mL} / \mathrm{min} / 1.73 \mathrm{~m}^{2}$ $(P=0.031)$. HS Trop T levels were significantly higher in all CKD patients with $\mathrm{CAD}$ than in the non-CAD group ( 0.4973 versus $0.0384 \mathrm{ng} / \mathrm{mL}, P=0.008)$, and when classified by stage in CKD 3 but not in 5 (Table 1). Two factors were significantly associated with CAD by multivariate logistic regression analysis (Table 2). Female sex and HS Trop T levels had adjusted ORs (95\% confidence interval) of 0.51 (0.26-0.98) and 5.92 (3.02-11.60).

For all CKD patients, the cutoff points for HS Trop T and $\mathrm{CAD}$ are shown in Table 3 and Figure 1. The area under the ROC curve was $77.15 \%$, giving sensitivity and specificity of $65.91 \%$ and $75.65 \%$, respectively, for the cutoff point of $0.041 \mathrm{ng} / \mathrm{mL}$. The cutoff point of HS Trop T at 0.041 gave sensitivity and specificity of $67.31 \%$ and $79.03 \%$ (CKD stage 3; Table 4 and Figure 2 ) and $71.43 \%$ and $56.25 \%$ (CKD stages 4 and 5; Table 5 and Figure 3), respectively.

\section{Discussion}

Third-generation Trop $\mathrm{T}$ has been shown to be a predictor of future CAD and associated with mortality in CKD patients. ${ }^{10,11}$ This study added the correlation of HS Trop T and significant coronary occlusion with an adjusted OR of 5.92 in CKD patients (Table 2). Sex is another significant factor (Table 2). As in previous reports, males were at higher 
Table I Characteristics of all patients categorized by presence of coronary artery disease (CAD) from coronary angiograms

\begin{tabular}{|c|c|c|c|c|}
\hline & $\begin{array}{l}\text { All patients } \\
n=210\end{array}$ & $\begin{array}{l}\text { CAD } \\
n=132\end{array}$ & $\begin{array}{l}\text { Non-CAD } \\
n=78\end{array}$ & $P$-value \\
\hline Mean age, years $\pm S D$ & $71.02 \pm 9.49$ & $71.17 \pm 9.59$ & $70.76 \pm 9.37$ & 0.766 \\
\hline Male sex, n (\%) & $127(60.48)$ & $89(67.42)$ & $38(48.72)$ & 0.007 \\
\hline \multicolumn{5}{|l|}{ Comorbid diseases, n (\%) } \\
\hline Hypertension & $160(76.19)$ & $103(78.03)$ & $57(73.08)$ & 0.415 \\
\hline Diabetes mellitus & $103(49.05)$ & $74(56.06)$ & $29(33.18)$ & 0.008 \\
\hline Dyslipidemia & $90(42.86)$ & $57(43.18)$ & $32(42.31)$ & 0.902 \\
\hline Pulmonary disease & $28(13.33)$ & $16(12.12)$ & $12(15.38)$ & 0.501 \\
\hline Connective tissue disease & $3(1.43)$ & $2(1.52)$ & $\mathrm{I}(\mathrm{I} .28)$ & 1.000 \\
\hline Stroke & $25(11.90)$ & 17 (I2.88) & $8(10.26)$ & 0.571 \\
\hline Cirrhosis & $3(1.43)$ & $3(2.27)$ & 0 & 0.296 \\
\hline Cancer & $13(6.15)$ & $6(4.55)$ & $7(8.97)$ & 0.240 \\
\hline Post-PTCA & $54(25.7 I)$ & $31(23.48)$ & $23(29.49)$ & 0.336 \\
\hline Previous CAD & $35(16.67)$ & $24(18.18)$ & II (14.10) & 0.443 \\
\hline \multicolumn{5}{|l|}{ Other factors } \\
\hline Family history of CAD & $2(0.95)$ & $2(1.52)$ & 0 & 0.531 \\
\hline Chest pain more than twice in 24 hours & 75 (37.29) & $51(38.64)$ & $21(26.92)$ & 0.084 \\
\hline Smoking & $13(6.19)$ & $8(6.06)$ & $5(6.4 I)$ & 1.000 \\
\hline Aspirin use & $135(64.29)$ & $87(65.91)$ & $48(6 I .5 I)$ & 0.523 \\
\hline \multicolumn{5}{|l|}{ TIMI risk score } \\
\hline Mean \pm SD & $2.74 \pm 1.29$ & $2.90 \pm 1.31$ & $2.46 \pm 1.22$ & 0.015 \\
\hline \multicolumn{5}{|l|}{ TIMI categories } \\
\hline Low risk (TIMI I, 2) & $101(48.10)$ & $60(45.45)$ & $4 \mid(52.56)$ & 0.290 \\
\hline Moderate risk (TIMI 3, 4) & $87(4 I .43)$ & $55(4 I .67)$ & $32(4 I .03)$ & \\
\hline High risk (TIMI 5, 6) & $22(10.48)$ & $17(12.88)$ & $5(6.4 I)$ & \\
\hline Electrocardiographic findings & & & & 0.004 \\
\hline Non-myocardial infarction & $136(64.76)$ & $75(56.82)$ & $61(78.21)$ & \\
\hline ST-elevation myocardial infarction & $18(8.57)$ & $16(12.12)$ & $2(2.56)$ & \\
\hline Non-ST-elevation myocardial infarction & $56(26.67)$ & $41(31.06)$ & $15(19.23)$ & \\
\hline eGFR $\left(\mathrm{mL} / \mathrm{min} / \mathrm{l} .73 \mathrm{~m}^{2}\right)$ & & & & 0.031 \\
\hline Mean \pm SD & $40.36 \pm 0.87$ & $38.91 \pm 1.13$ & $42.8 \mathrm{I} \pm 1.32$ & \\
\hline \multicolumn{5}{|l|}{ eGFR by category } \\
\hline CKD stage 3 & $166(79.05)$ & 104 (78.79) & $62(79.79)$ & 0.094 \\
\hline CKD stage 4 & $37(17.62)$ & $21(15.91)$ & $16(20.51)$ & \\
\hline CKD stage 5 & $7(3.33)$ & $7(5.30)$ & 0 & \\
\hline HS Trop T (ng/mL) & & & & 0.008 \\
\hline Mean $\pm S D$ & & $0.4973 \pm 1.5186$ & $0.0384 \pm 0.0534$ & \\
\hline \multicolumn{5}{|l|}{ HS Trop T $(\mathrm{ng} / \mathrm{mL})$ by CKD category } \\
\hline CKD stage 3 & & $0.5152 \pm 1.6712$ & $0.0304 \pm 0.0307$ & 0.023 \\
\hline CKD stages 4 and 5 & & $0.4306 \pm 0.7272$ & $0.0693 \pm 0.0976$ & 0.055 \\
\hline
\end{tabular}

Abbreviations: SD, standard deviation; PTCA, percutaneous transluminal coronary angioplasty; TIMI, thrombolysis in myocardial infarction; eGFR, estimated glomerular filtration rate; CKD, chronic kidney disease; HS Trop T, high-sensitivity troponin T.

Table 2 Factors associated with coronary artery disease by coronary angiogram using multivariate logistic regression analysis

\begin{tabular}{llll}
\hline Factors & $\begin{array}{l}\text { Adjusted } \\
\text { odds ratio }\end{array}$ & $\begin{array}{l}\text { 95\% confidence } \\
\text { interval }\end{array}$ & P-value \\
\hline Female sex & $0.5 \mathrm{I}$ & $0.26-0.98$ & 0.044 \\
Diabetes mellitus & 1.53 & $0.79-2.98$ & 0.204 \\
Frequent chest pain & 1.39 & $0.57-3.4 \mathrm{I}$ & 0.462 \\
eGFR & 0.98 & $0.96-1.01$ & 0.422 \\
TIMI score & 1.20 & $0.85-1.68$ & 0.289 \\
HS Trop T & 5.92 & $3.02-11.60$ & $<0.00 \mathrm{I}$ \\
\hline
\end{tabular}

Note: Frequent chest pain: chest pain more than two times in 24 hours.

Abbreviations: eGFR, glomerular filtration rate; TIMI, thrombolysis in myocardial infarction; HS Trop T, high-sensitivity troponin T.
Table 3 Diagnostic properties of various high-sensitivity troponin $\mathrm{T}$ (HS Trop $\mathrm{T}$ ) levels and coronary artery disease in all patients with chronic kidney diseases ( $n=2$ I 0; area under ROC curve $=0.77$ I5)

\begin{tabular}{|c|c|c|c|c|c|}
\hline $\begin{array}{l}\text { HS Trop T } \\
\text { (ng/mL) }\end{array}$ & 0.014 & 0.030 & 0.036 & 0.041 & 0.100 \\
\hline Sensitivity & $92.42 \%$ & $76.52 \%$ & $68.94 \%$ & $65.91 \%$ & $43.94 \%$ \\
\hline Specificity & $28.21 \%$ & $58.97 \%$ & $71.79 \%$ & $75.64 \%$ & $91.03 \%$ \\
\hline $\begin{array}{l}\text { Positive predictive } \\
\text { value }\end{array}$ & $68.54 \%$ & $75.94 \%$ & $80.53 \%$ & $82.08 \%$ & $89.23 \%$ \\
\hline $\begin{array}{l}\text { Negative predictive } \\
\text { value }\end{array}$ & $68.75 \%$ & $59.74 \%$ & $57.73 \%$ & $56.73 \%$ & $48.97 \%$ \\
\hline
\end{tabular}

Abbreviation: ROC, receiver operating characteristic. 


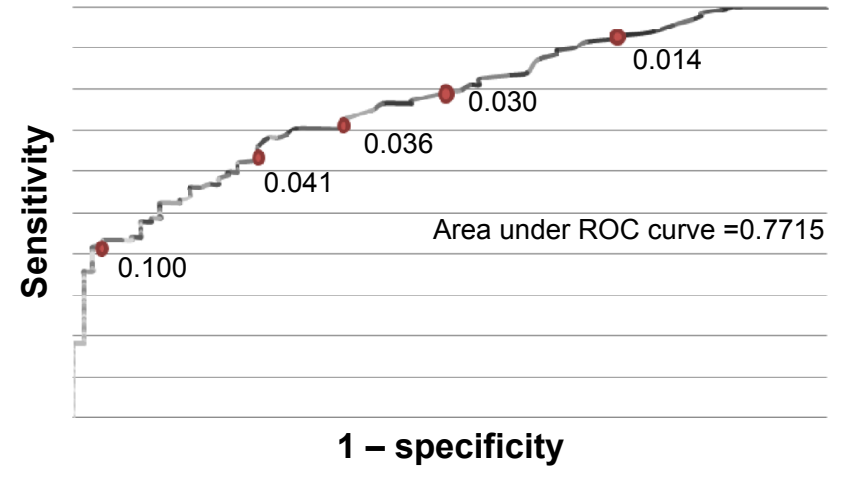

Figure I Receiver operating characteristic (ROC) curve of high-sensitivity troponin $T$ levels and coronary artery disease in all patients $(n=2 \mid 0)$.

risk for $\mathrm{CAD}$ than females. After adjustment by multivariate logistic regression analysis, TIMI score and GFR became nonsignificant factors for coronary occlusion (Tables 1 and 2). These results may indicate that sex and HS Trop T levels were the only two independent factors associated with significant coronary occlusion, but not GFR level or disease severity.

A study from France suggested using an HS Trop T cutoff point at $0.0358 \mathrm{ng} / \mathrm{mL}$ for acute myocardial infarction in patients with CKD. Its sensitivity and specificity were $94 \%$ and $86 \%$, respectively. ${ }^{12}$ Another study conducted in the US compared HS Trop T levels in 51 CKD patients with 112 normal renal function patients who had ACS. ${ }^{7}$ The sensitivity of ACS diagnosis increased from $63 \%$ to $87 \%$ if the cutoff point of HS Trop T increased from 0.1 to $0.5 \mathrm{ng} / \mathrm{mL}$. For a Thai population, the Trop T level of $0.1 \mathrm{ng} / \mathrm{mL}$ gave sensitivity of $90.90 \%$ and specificity of $84.50 \%$ in CKD patients with suspected ACS compared with CKD patients without ACS symptoms. ${ }^{13}$ Other studies also showed that the cutoff point for HS Trop T to diagnose acute myocardial infarction needs to be adjusted by the GFR. ${ }^{14-16}$

In this study, the cutoff point of HS Trop T at $0.041 \mathrm{ng} / \mathrm{mL}$ gave sensitivities from $65.91 \%$ to $71.45 \%$ and specificities of

Table 4 Diagnostic properties of various high-sensitivity troponin T (HS Trop T) levels and coronary artery disease in patients with chronic kidney disease stage $3(n=166$; area under ROC curve $=0.7876$ )

\begin{tabular}{|c|c|c|c|c|c|}
\hline $\begin{array}{l}\text { HS Trop T } \\
\text { (ng/mL) }\end{array}$ & 0.014 & 0.036 & $0.04 I$ & 0.046 & 0.075 \\
\hline Sensitivity & $90.38 \%$ & $69.23 \%$ & $67.31 \%$ & $64.42 \%$ & $50.96 \%$ \\
\hline Specificity & $33.87 \%$ & $75.81 \%$ & $79.03 \%$ & $80.65 \%$ & $88.71 \%$ \\
\hline $\begin{array}{l}\text { Positive predictive } \\
\text { value }\end{array}$ & $69.63 \%$ & $82.35 \%$ & $85.19 \%$ & $84.81 \%$ & $88.33 \%$ \\
\hline $\begin{array}{l}\text { Negative predictive } \\
\text { value }\end{array}$ & $67.74 \%$ & $58.02 \%$ & $58.82 \%$ & $57.47 \%$ & $51.89 \%$ \\
\hline
\end{tabular}

Abbreviation: ROC, receiver operating characteristic.

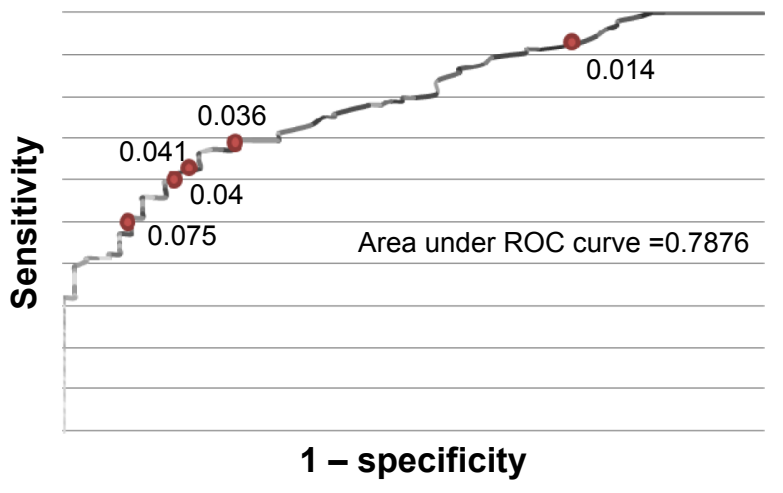

Figure 2 Receiver operating characteristic (ROC) curve of high-sensitivity troponin T levels and coronary artery disease in chronic kidney disease stage $3(n=166)$.

$71.43 \%$ and $79.03 \%$ overall and CKD stage 3, respectively. Specificity dropped to $56.25 \%$ in CKD stage 4 and 5 (Table 4 and 5). The decreasing of sensitivities by GFR may explain by the high baseline HS Trop T level in low GFR. ${ }^{14-16}$ Note that these diagnostic properties were indications of coronary occlusion by coronary angiogram, not for diagnosis of acute myocardial infarction as in previous studies. ${ }^{12-16}$

The strength of this study is that all subjects had coronary angiograms performed to confirm the CAD. There are some limitations in this study, including small sample size, retrospective data collection, and generation of HS Trop T. The results therefore may not be applicable for the newer generations of Trop T or another cardiac marker (troponin I). The study population was limited, due to the use of newergeneration HS Trop $\mathrm{T}$ in this hospital. Finally, due to the retrospective study design, the study population in the CAD and non-CAD groups may not have been equally distributed. The numbers of patients with high TIMI score, CKD stage 4, and CKD stage 5 were higher in the CAD group than the non-CAD group $(12.88 \%$ versus $6.41 \% ; 15.91 \%$ versus $20.51 \% ; 5.30 \%$ versus $0 \%$ ), as shown in Table 1 . However, after controlling of these factors by using multivariate logistic

Table 5 Diagnostic properties of various high-sensitivity troponin T (HSTrop T) levels and coronary artery disease in patients with chronic kidney disease stages 4 and $5(n=44$; area under ROC curve $=0.7188$ )

\begin{tabular}{lllllll}
\hline $\begin{array}{l}\text { HS Trop T } \\
\text { (ng/mL) }\end{array}$ & $\mathbf{0 . 0 3 6}$ & $\mathbf{0 . 0 4 1}$ & $\mathbf{0 . 0 7 5}$ & $\mathbf{0 . 1 0 0}$ & $\mathbf{0 . 1 5 0}$ & $\mathbf{0 . 2 0 0}$ \\
\hline $\begin{array}{l}\text { Sensitivity } \\
\text { Specificity }\end{array}$ & $75.00 \%$ & $71.43 \%$ & $57.14 \%$ & $50.00 \%$ & $50.00 \%$ & $46.43 \%$ \\
$\begin{array}{l}\text { Positive } \\
\text { predictive value }\end{array}$ & $75.25 \%$ & $56.25 \%$ & $75.00 \%$ & $87.50 \%$ & $93.75 \%$ & $93.75 \%$ \\
$\begin{array}{l}\text { Negative } \\
\text { predictive value }\end{array}$ & $56.25 \%$ & $47.00 \%$ & $80.00 \%$ & $87.50 \%$ & $93.33 \%$ & $92.86 \%$ \\
\hline
\end{tabular}

Abbreviation: ROC, receiver operating characteristic. 


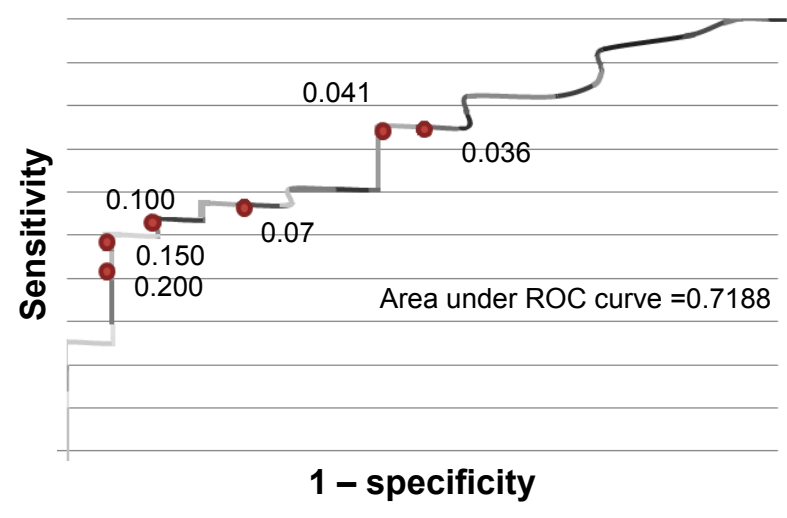

Figure 3 Receiver operating characteristic (ROC) curve of high-sensitivity troponin $\mathrm{T}$ levels and coronary artery disease in chronic kidney disease stages 4 and 5 $(n=44)$.

regression analysis, both TIMI score and CKD stage were not an independent factor for having CAD.

\section{Conclusion}

The HS Trop T level of $0.041 \mathrm{ng} / \mathrm{mL}$ provided diagnostic properties for established coronary artery occlusion in chronic kidney disease patients.

\section{Acknowledgment}

We would like to thank Professor James A Will (University of Wisconsin) for his kind review of the paper.

\section{Disclosure}

The authors report no conflicts of interest in this work.

\section{References}

1. World Health Organization. Cardiovascular Diseases (CVDs): Fact Sheet 317. 2015. Available from: http://www.who.int/mediacentre/factsheets/ fs317/en. Accessed July 6, 2015.

2. O'Connor RE, Brady W, Brooks SC, et al. Part 10: acute coronary syndromes: 2010 American Heart Association Guidelines for Cardiopulmonary Resuscitation and Emergency Cardiovascular Care. Circulation. 2010;122:S787-S817.
3. Hamm CW, Bassand JP, Agewall S, et al. ESC guidelines for the management of acute coronary syndromes in patients presenting without persistent ST-segment elevation: the Task Force for the management of acute coronary syndromes (ACS) in patients presenting without persistent ST-segment elevation of the European Society of Cardiology (ESC). Eur Heart J. 2011;32:2999-3054.

4. Thygesen K, Alpert JS, White HD, et al. Universal definition of myocardial infarction. Circulation. 2007;116:2634-2653.

5. Christenson RH, Phillips D. Sensitive and high sensitivity next generation cardiac troponin assays: more than just a name. Pathology. 2011; 43:213-219.

6. Hamm CW, Giannitsis E, Katus HA. Cardiac troponin elevations in patients without acute coronary syndrome. Circulation. 2002;106: 2871-2872.

7. Van Lente F, McErlean ES, DeLuca SA, Peacock F, Rao JS, Nissen SE. Ability of troponin to predict adverse outcomes in patients with renal insufficiency and suspected acute coronary syndromes: a case-matched study. J Am Coll Cardiol. 1999;33:471-478.

8. Chotivanawan T, Krittayaphong R. Normal range of serum highlysensitive troponin-T in patients with chronic kidney disease stage 3-5. J Med Assoc Thai. 2012;95 Suppl 2:S127-S132.

9. Antman EM, Cohen M, Bernink PJ, et al. The TIMI risk score for unstable angina/non-ST elevation MI: a method for prognostication and therapeutic decision making. JAMA. 2000;284:835-842.

10. Apple FS, Murakami MM, Pearce LA, Herzog CA. Predictive value of cardiac troponin I and $\mathrm{T}$ subsequent death in end-stage renal disease. Circulation. 2002;106:2941-2945.

11. Aviles RJ, Askari AT, Lindahl B, et al. Troponin T levels in patients with acute coronary syndromes, with or without renal dysfunction. N Engl J Med. 2002;346:2047-2052.

12. Chenevier-Gobeaux C, Meune C, Freund Y, et al. Influence of age and renal function on high-sensitivity cardiac troponin $\mathrm{T}$ diagnostic accuracy for the diagnosis of acute myocardial infarction. Am J Cardiol. 2013; 111:1701-1707.

13. Sukonthasarn A, Ponglopisit S. Diagnostic level of cardiac troponin $T$ in patients with chronic renal dysfunction, a pilot study. J Med Assoc Thai. 2007;90:1749-1758.

14. Parikh RH, Seliger SL, deFilippi CR. Use and interpretation of high sensitivity cardiac troponins in patients with chronic kidney disease with and without acute myocardial infarction. Clin Biochem. 2015;48: $247-253$.

15. Dubin RF, Li Y, He J, et al. Predictors of high sensitivity cardiac troponin $\mathrm{T}$ in chronic kidney disease patients: a cross-sectional study in the chronic renal insufficiency cohort (CRIC). BMC Nephrol. 2013; 14:229.

16. Pfortmueller CA, Funk GC, Marti G, et al. Diagnostic performance of high-sensitive troponin $\mathrm{T}$ in patients with renal insufficiency. $\mathrm{Am}$ J Cardiol. 2013;112:1968-1972.
Therapeutics and Clinical Risk Management

\section{Publish your work in this journal}

Therapeutics and Clinical Risk Management is an international, peerreviewed journal of clinical therapeutics and risk management, focusing on concise rapid reporting of clinical studies in all therapeutic areas, outcomes, safety, and programs for the effective, safe, and sustained use of medicines. This journal is indexed on PubMed Central, CAS,

\section{Dovepress}

EMBase, Scopus and the Elsevier Bibliographic databases. The manuscript management system is completely online and includes a very quick and fair peer-review system, which is all easy to use. Visit http://www.dovepress.com/testimonials.php to read real quotes from published authors. 